\title{
TRIBROMOPHENOL DEGRADATION BY A CATECHOL-DRIVEN FENTON REACTION
}

\section{DAVID CONTRERAS ${ }^{*}$, CLAUDIA OVIEDO ${ }^{2}$, ROBERTO VALENZUELA ${ }^{3}$, JUANITA FREER ${ }^{3}$, KIMENA ROJO ${ }^{3}$ JAIME RODRÍGUEZ}

\author{
${ }^{1}$ Department of Analytical and Inorganic Chemistry, Faculty of Chemical Sciences, Universidad de Concepción, Chile \\ ${ }^{2}$ Department of Chemistry, Faculty of Sciences, Universidad del Bio-Bio, Chile \\ ${ }^{3}$ Renewable Resources Laboratory, Biotechnology Center, Universidad de Concepción, Chile \\ *Corresponding author. Tel.: +56-41-2207433; Fax: +56-41-245974
}

(Received: September 2, 2008 - Accepted: November 10, 2008)

\begin{abstract}
Tribromophenol (TBP) is a halogenated phenol mainly used as an intermediate of flame retardants in the electronics manufacturing industry as well as a fungicide in the wood industry to prevent fungal wood stain and decay. As a result of this massive use, its bio-availability, toxicity, and environmental fate are of increasing concern worldwide.

TBP degradation by a catechol (CAT)-driven Fenton reaction was studied. In order to achieve the best yield in TBP degradation, an experimental design was applied for multivariate optimization of the experimental degrading system variables. At optimized concentrations, the CAT- driven Fenton reaction yielded $75 \%$ TBP degradation in $2 \mathrm{~h}$ at room temperature. The multivariate optimization showed that the highest TBP degradation (1 mol base) was obtained at a ratio of CAT: $\mathrm{FeCl}_{3}: \mathrm{H}_{2} \mathrm{O}_{2}=0.150: 0.211: 5.100$ at $\mathrm{pH}=3.4$.

A time course degradation of TBP comparing the CAT-driven Fenton reaction with the classical Fenton reaction is also presented. During the first hours of reaction (up to $8 \mathrm{~h}$ ), increased degradation efficiencies were observed in the CAT-driven Fenton reaction in comparison with the conventional Fenton reaction. Possible causes for the observed behavior are also discussed.
\end{abstract}

Keywords: Fenton, tribromophenol, catechol, degradation

\section{INTRODUCTION}

2,4,6-tribromophenol (TBP) is the most widely produced brominated phenol. The production volume of TBP has been estimated at approximately 2500 tons/year in Japan and 9500 tons/year worldwide in 2001'. This molecule is mainly used as a reactive flame retardant intermediate, being applied in the production line of electronic devices such as TVs, computers and other household items. It is also used as a wood preservative biocide to prevent wood fungal deterioration.

In recent years in Chile, its sodium salt (TBPNa) has been used to prevent wood stain and decay, substituting sodium pentachlorophenate (PCPNa) ${ }^{2}$.

As a result of this massive application, TBP can be now found in soils, waters and sawdust. In sawmills, high concentrations of the compound have been found ${ }^{3,4}$.

In 1998, the Environmental Protection Agency (EPA, USA) incorporated TBP into the list of hazardous wastes ${ }^{5}$. Since then, there has been increasing concern worldwide about its potential toxicity ${ }^{6}$, and endocrine disrupting potency ${ }^{7}$.

In recent years, there has been great interest in the use of advanced oxidation processes (AOPs) for the degradation and mineralization of hazardous and recalcitrant compounds ${ }^{8}$. These technologies include Fenton treatment $\left(\mathrm{Fe}^{+2} /\right.$ $\mathrm{H}_{2} \mathrm{O}_{2}, \mathrm{O}_{3} / \mathrm{H}_{2} \mathrm{O}_{2}, \mathrm{H}_{2} \mathrm{O}_{2} / \mathrm{UV}$, photocatalysis, photo-assisted Fenton and sonolysis. Other Fenton-type reactions used as AOPs include small amounts of iron reducing phenolic compounds ${ }^{9}$. These Fenton-type reactions are promoted by dihydroxybenzenes (DHBs), such as catechol (CAT), which can chelate and reduce $\mathrm{Fe}(\mathrm{III})$ enhancing $\mathrm{OH}^{\cdot}$ production ${ }^{10}$.

Diverse compounds have been degraded by this system as Aguiar et al 2007 have extensively reviewed ${ }^{9}$. Benzylic compounds, such as benzene, anisole, nitro- and chloro-benzene ${ }^{11}$, veratryl alcohol ${ }^{12}$, malachite green Chen et al., 2002 $2^{13}, \mathrm{PAHs}^{14}$, and chlorophenols as well a paper mill bleaching effluent have also been degraded ${ }^{15,16}$. Degradation on an aliphatic compound such as EDTA has also been reported ${ }^{17}$.

In this study, the effectiveness of the CAT-driven Fenton reaction on TBP degradation was assessed. A factorial experimental design, which is a multivariate optimization strategy, was utilized to obtain optimal values for the main parameters for TBP degradation by the CAT-driven Fenton reaction. A time-course comparison of TBP degradation by this system versus a classical Fenton reaction is also presented.

\section{EXPERIMENTAL}

Reagents

All the experiments and analyses used nanopure water (NPW). All the reagents were p.a. grade unless otherwise stated. Catalase (bovine liver) was obtained from Sigma. 1,2 dihydroxybenzene (CAT) was purchased from Aldrich. Hydrogen peroxide $\left(\mathrm{H}_{2} \mathrm{O}_{2}\right) 30 \%(\mathrm{w} / \mathrm{w})$ was purchased from Fluka. TBP, ferric chloride, ferrous sulfate, disodium hydrogen phosphate, sodium dihydrogen phosphate, acetic acid (HPLC grade) were obtained from Merck. Methanol (HPLC grade) was purchased from J.T. Baker.

$\mathrm{Fe}(\mathrm{II})$ (prepared immediately before each experiment) and $\mathrm{Fe}(\mathrm{III})$ were dissolved in $\mathrm{HCl} 0.01 \mathrm{M}$. The $\mathrm{H}_{2} \mathrm{O}_{2}$ concentrations were standarized by titration with $\mathrm{KMnO}_{4}$ solution just before each treatment.

\section{Analyses}

HPLC- analyses: The degradation of TBP was monitored by HPLC using a Lichrocart 125-4/Lichrospher $100 \mathrm{RP}-18$ (5 $\mu \mathrm{m}$ particle diameter) column, with a $100 \mu \mathrm{L}$ loop. Triplicate injection of each sample was performed. A HPLC pump (Knauer) with constant flow of $0.6 \mathrm{~mL} \mathrm{~min}-1$. Mobile phase: $0.7 \%$ acetic acid, $69.3 \%$ methanol, $30 \%$ nanopure water, $\mathrm{pH}: 3$. Detection was performed with a UV -VIS detector (Knauer, Variable Wavelength Monitor) at a wavelength of $290 \mathrm{~nm}$. Total organic carbon (TOC) was determined using a total carbon analyzer (TOC-5000; Shimadzu Co.; Ltd. Japan). AOX was determined in Euroglas ESC 1000 system.

\section{Residual $\mathrm{H}_{2} \mathrm{O}_{2}$ measurements}

Buffer solution: Phosphate buffer $150 \mathrm{mM} \mathrm{pH:7} \mathrm{was} \mathrm{prepared} \mathrm{in} \mathrm{nanopure}$ water (which was degassed by boiling for 10 minutes; cooled to $25^{\circ} \mathrm{C}$, and finally passed through a $\mathrm{N}_{2}$ current for 20 minutes). Residual $\mathrm{H}_{2} \mathrm{O}_{2}$ was determined as follows: in a sealed reactor, $18 \mathrm{~mL}$ of each sample was added to $11 \mathrm{~mL}$ of phosphate buffer in the dark. The mixture was then passed through a $\mathrm{N}_{2}$ current. Then, $1 \mathrm{~mL}$ of catalase $\left(1.48 \times 10^{-2} \mathrm{IU}\right)$ was added, the released oxygen was measured by a dissolved oxygen electrode (Extech Instruments).

\section{Procedures}

Experimental design: Response surface methodology (RSM) was used. The model used was the central composite design consisting in a factorial design. The variable values were coded and normalized in unitary values: -1 is defined as the lowest value of a variable and +1 as its highest value. From these extreme values of variables, the central point (coded 0 ) was set and assayed in triplicate. The star points were distributed at a distance of $n^{1 / 2}$ from the central point, where $\mathrm{n}$ is the number of variables ${ }^{18}$. The influence of the four following variables was studied: CAT concentration, $\mathrm{Fe}(\mathrm{III})$ concentration $\left(\mathrm{X}_{1}\right)$, and $\mathrm{H}_{2} \mathrm{O}_{2}$ concentration $\left(\mathrm{X}_{2}\right)$. The response was TBP degradation $(\mathrm{Y})$, expressed as a percentage of the initial amount. The experimental design is shown in table 1 . 
Tabla 1.- Experimental and calculated degradation on of TBP by the CATdriven Fenton reaction in the factorial design.

$\begin{array}{ccccc}\text { Fe III ( } \mu \mathrm{M}) & \mathrm{H}_{2} \mathrm{O}_{2}(\boldsymbol{\mu M}) & \mathrm{CAT}(\boldsymbol{\mu M}) & \begin{array}{c}\text { Experimental } \\ \text { results }\end{array} & \begin{array}{c}\text { Calculated } \\ \text { results }\end{array} \\ 13(-1) & 500(-1) & 13(-1) & 55.1 & 57.5 \\ 13(-1) & 500(-1) & 38(+1) & 60.5 & 61.4 \\ 38(+1) & 500(-1) & 13(-1) & 75.0 & 73.7 \\ 38(+1) & 500(-1) & 38(+1) & 72.9 & 77.6 \\ 13(-1) & 1000(+1) & 13(-1) & 68.1 & 71.9 \\ 13(-1) & 1000(+1) & 38(+1) & 78.0 & 75.8 \\ 38(+1) & 1000(+1) & 13(-1) & 91.0 & 88.1 \\ 38(+1) & 1000(+1) & 38(+1) & 89.0 & 92.0 \\ 25.5(0) & 750(0) & 4.47(-2) & 71.1 & 70.9 \\ 25.5(0) & 750(0) & 46.5(+2) & 80.3 & 77.5 \\ 4.47(-2) & 750(0) & 25.5(0) & 65.6 & 63.7 \\ 46.5(+2) & 750(0) & 25.5(0) & 92.0 & 90.9 \\ 25.5(0) & 330(-2) & 25.5(0) & 65.9 & 62.9 \\ 25,5(0) & 1170(+2) & 25.5(0) & 64.1 * & 87.1 \\ 25.5(0) & 750(0) & 25.5(0) & 86.0 & 88.3 \\ 25.5(0) & 750(0) & 25.5(0) & 88.0 & 88.3 \\ 25.5(0) & 750(0) & 25.5(0) & 92.0 & 88.3 \\ & & & \end{array}$

${ }^{2} \mathrm{TBP}$ degradation as a percentage of initial amount *Excluded Value

The initial concentration of TBP $(180 \mu \mathrm{M})$, temperature $\left(25^{\circ} \mathrm{C}\right)$ and reaction time $(12 \mathrm{~h})$ were kept constant. The optimized values of the analyzed variables were obtained from the maximum values of this function using the SIMPLEX method. The statistical validation was performed by an ANOVA test with a $95 \%$ of confidence. All the calculations were carried out by the Modde 7.0 software.

\section{RESULTS AND DISCUSSION}

\section{Experimental design}

Table 1 shows the experimental and calculated results from the factorial design applied as the multivariate optimization strategy for TBP degradation.

A normalized polynomial response to TBP degradation (Eq. 1) was obtained from the factorial design experiments.

The polynomial equation reveals the relative importance and interactions between the different variables.

$Y \%=7.43( \pm 0.37)+0.68 X_{1}( \pm 0.18)+0.60 X_{2}( \pm 0.22)+0.16 X_{3}( \pm 0.17)$ $-0.34 X 1_{2}^{2}\left( \pm 0.20-0.41 X 1_{2}^{2}( \pm 0.24)-0.43 X 1_{3}^{2}( \pm 0.20)\right.$,

where $\mathrm{Y}$ : is the TBP degradation, $\mathrm{X}_{1}$ the $\mathrm{Fe}(\mathrm{III})$ concentration, $\mathrm{X}_{2}$ the $\mathrm{H}_{2} \mathrm{O}_{2}$ concentration.

The positive first-order coefficients of Fe(III) concentration $\left(\mathrm{X}_{1}\right), \mathrm{H}_{2} \mathrm{O}_{2}\left(\mathrm{X}_{2}\right)$ concentration and CAT $\left(\mathrm{X}_{3}\right)$ concentration imply that increasing values of these three variables result in greater TBP degradation. The main effect (given from the normalized magnitude of the $\mathrm{X}_{1}$ coefficient) is due to $\mathrm{Fe}(\mathrm{III})$ concentration. The polynomial equation obtained also shows a negative second-order coefficient of the $\mathrm{Fe}(\mathrm{III}), \mathrm{H}_{2} \mathrm{O}_{2}$ and CAT concentrations, indicating a maximum region described by a parabolic behavior. The contour plots are predicted by the polynomial response, where the experimental assay area falls within the dotted rectangular line. In this area, the model's validity is guaranteed $(95 \%$ confidence); whereas outside this area, the validity is uncertain because it is an extrapolation of the system's behavior in a non-assayed region

Although CAT concentration variation is not relevant in this range, its presence is necessary for an enhanced TBP degradation. TBP degradation dependence on CAT concentration can be explained considering mechanistic evidence provided by Pingatello et al $^{19-22}$ for phenols degradation in Fenton and PhotoFenton systems. These mechanisms rely in a self-catalyzed Fenton reaction, produced by the generation of hydroxylated phenol species that continuously reduce $\mathrm{Fe}(\mathrm{III})$ to $\mathrm{Fe}(\mathrm{II})$. Hence, in the CAT-assisted Fenton reaction, CAT would be important at the initial stage, triggering the Fenton reaction, and afterwards the cyclic reduction of $\mathrm{Fe}$ (III) would proceed from the dihydroxybenzenes (DHBs) generated from TBP oxidation.

Furthermore, CAT maintains the $\mathrm{OH} \bullet$ production longer than the classical Fenton reaction ${ }^{10}$. This behavior has been associated with the presence of the [CAT-Fe(III)] complex ${ }^{10,12}$.

The multivariate optimization strategy provided the best conditions predicted for the main parameters involved in TBF degradation by the CATdriven Fenton reaction. Table 2 summarizes the optimum concentrations found for $\mathrm{Fe}(\mathrm{III})$ and $\mathrm{H}_{2} \mathrm{O}_{2}$ and CAT in $12 \mathrm{~h}$ reaction.

Table 2.- Optimized values of the variables obtained from the response surface methodology.

\begin{tabular}{ccc} 
Variable & Relation & Value $^{\mathbf{2}}$ \\
\hline $\mathrm{TBF}$ & 1 & 180 \\
$\mathrm{Fe}(\mathrm{III})\left(\mathrm{X}_{1}\right)$ & 0.211 & 38 \\
$\mathrm{CAT}\left(\mathrm{X}_{2}\right)$ & 0.150 & 27 \\
$\mathrm{H}_{2} \mathrm{O}_{2}\left(\mathrm{X}_{4}\right)$ & 5.100 & 918 \\
\hline \multicolumn{2}{c}{${ }^{\mathrm{a}}$ Units: $10^{-6} \mathrm{Mol}$ ar }
\end{tabular}

In Fig. 1, the contour plots of the polynomial response are shown. In the experiments leading to this graph, the CAT concentration was $27 \mu \mathrm{M}$.

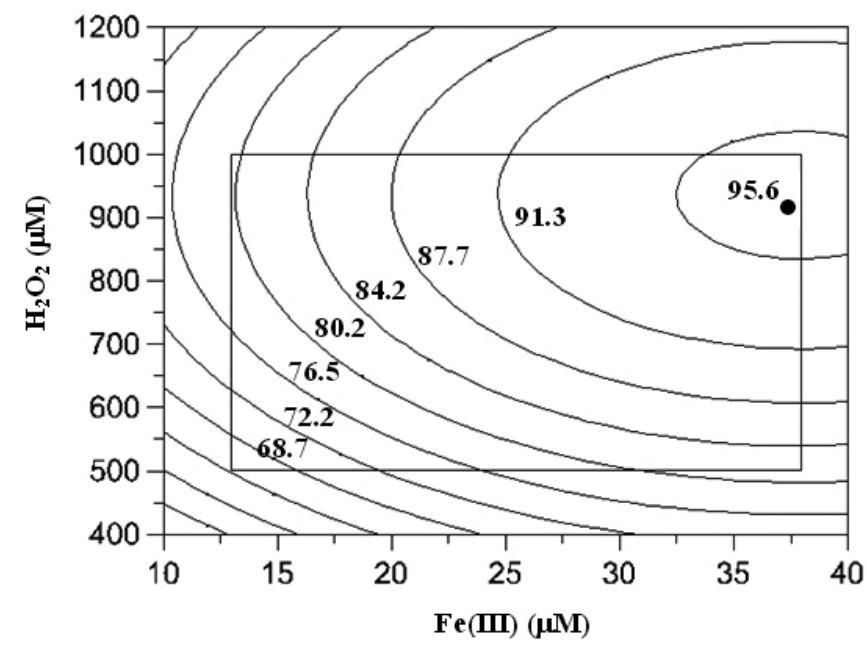

Figure 1. Response surface for the TBP degradation as a function of $\mathrm{Fe}(\mathrm{III})$ and $\mathrm{H}_{2} \mathrm{O}_{2}$ concentration. $\mathrm{CAT}=27 \mu \mathrm{M}$. The experimental results are inside the rectangle. The black point indicates the selected optimal value.

Degradation and mineralization of TBP at optimized conditions

Time course degradation of TBP by the CAT-driven Fenton reaction and classical Fenton reaction was assessed (Fig. 2). An increased degradation rate was observed in the CAT-driven Fenton system in comparison with the classical Fenton reaction. This result is most evident at the initial stages of reaction. Thus, while 2 hours of a CAT-driven Fenton system yields $75 \%$ TBP degradation, the classical Fenton system only yields 45\% TBP degradation. This tendency persists for reaction times under 8 hours; afterwards, both treatments show similar efficiencies, especially after 13 hours of reaction. 


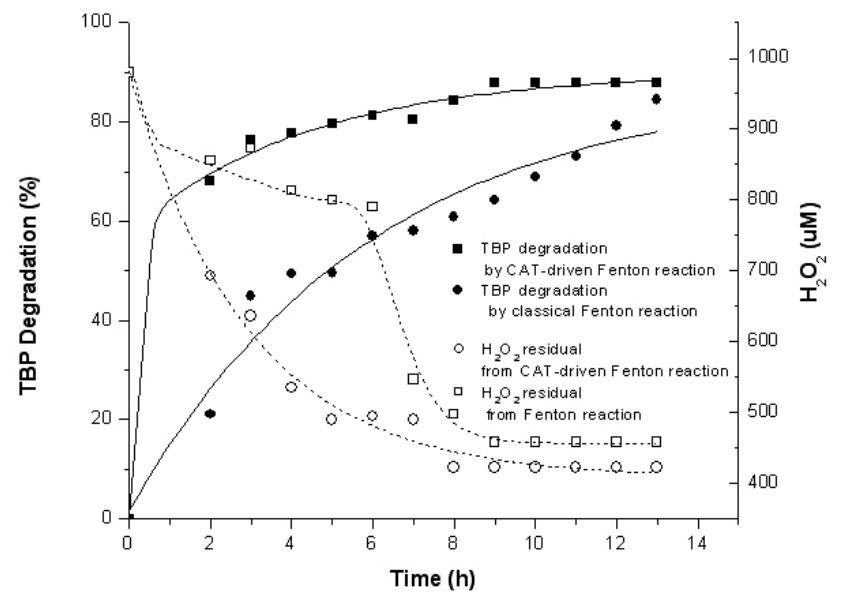

Figure 2. Time course of TBP degradation by CAT-driven Fenton reaction (!) and classical Fenton reaction (,) as compared to $\mathrm{H}_{2} \mathrm{O}_{2}$ residual from CATdriven Fenton reaction (") and classical Fenton reaction (-).

This time course comparison was performed using the optimized parameters found for the CAT-driven reaction, and the literature recommended parameters $^{23}$ in the classical Fenton reaction.

TBP degradation was tested using $\mathrm{UV} / \mathrm{TiO}_{2}$ photocatalysis ${ }^{24}$. An hour treatment of $0.5 \mathrm{~m}$ M TBP achieved $44 \%$ degradation, whereas $0.1 \mathrm{mM}$ TBP achieved $70 \%$ degradation. Hence, the CAT-driven Fenton reaction yielded a similar degradation rate of TBP $(75 \%)$ at an initial concentration of $0.18 \mathrm{mM}$.

Figure 2 also shows time-course residual $\mathrm{H}_{2} \mathrm{O}_{2}$ measurements. TBP degradation proceeds consuming peroxide until 8 hours of reaction in the CAT-driven Fenton reaction. Afterwards, TBP and $\mathrm{H}_{2} \mathrm{O}_{2}$ concentration remain constant. On the other hand, in the classical Fenton treatment, the $\mathrm{H}_{2} \mathrm{O}_{2}$ concentration decreases until 9 hours; afterwards, the $\mathrm{H}_{2} \mathrm{O}_{2}$ concentration remains constant but TBP degradation continues, suggesting a non $\mathrm{OH}^{*}$ mediated degradation, which could be due to TBP degradation by $\mathrm{Fe}(\mathrm{III})$ as described by Pracht et al for phenolic compounds ${ }^{25}$.

It should be noted that this phenolic substrate reached similar degradation rates after $12 \mathrm{~h}$ in the CAT-driven and the classical Fenton reaction. However, with non-phenolic substrates such as EDTA and veratrylic alcohol, the CATdriven Fenton reaction always yields higher degradation rates than the classical Fenton reaction, even at large time scales ${ }^{12,17}$.

The AOX removal after $12 \mathrm{~h}$ in the optimized treatment, and also in the classical Fenton treatment was determined, yielding approximately $30 \%$ in both cases. It should be noted that there is no increase in the AOX content despite the CAT presence. Previously, it has also been shown that there is no difference between the toxicity of the TBP solution and the TBP CAT-driven Fenton treated solution $\mathrm{s}^{26}$. This result suggests that, in the concentration range assayed, no additional AOX is generated via bromination of the CAT ring; which is highly convenient since the abatement of a brominated hydrocarbon is the ultimate goal of this research.

No significant difference in TBP mineralization was observed between the optimized treatment and the classical Fenton treatment. A mineralization rate near $13 \%$ was found in both cases.

The high degradation yields and limited mineralization rate of the Fentontype systems is in accordance with reports that use these CAT driven Fenton reactions as a previous step for a biological treatment ${ }^{26,27}$.

\section{CONCLUSIONS}

In the concentration ranges studied, TBP degradation by CAT-driven Fenton treatment was only dependent on $\mathrm{Fe}(\mathrm{III})$ and $\mathrm{H}_{2} \mathrm{O}_{2}$, as described by the multivariate design results.

Although no significant differences were found between the CAT-driven Fenton and classical Fenton treatments with respect to the TBP mineralization rate and AOX removal rate, TBP degradation efficiency by the CAT-driven Fenton treatment is higher than the classical Fenton during the first 8 hours of reaction.

In the CAT-driven Fenton system, TBP degradation only proceeds as long as there is $\mathrm{H}_{2} \mathrm{O}_{2}$ available, whereas in the classical Fenton treatment there is further TBP degradation even if all the $\mathrm{H}_{2} \mathrm{O}_{2}$ has been consumed (suggesting a non $\mathrm{OH}^{\cdot}$ mediated mechanism).

In all, these results provide further evidence of the applicability of the CATdriven Fenton reaction as a pollutant removal approach, yielding at optimized concentrations a $75 \%$ TBP degradation rate in $2 \mathrm{~h}$ at room temperature.

\section{ACKNOWLEDGMENTS}

Financial support from DIUC grant $\mathrm{N}^{\circ}$ 206.021.024-1.0 and FONDECYT 1070478 are gratefully acknowledged.

\section{REFERENCES}

(1) International Programme on Chemical Safety (IPCS) CICAD $\mathrm{N}^{\circ} 66$. http://www.who.int/ipcs/publications/cicad/cicad 66 web version.pdf.

(2) CONAMA Rubro aserraderos y procesos de madera. Guía para el control y prevención de la. contaminación industrial. Chile; National Commission of the Environment.http://www.conama.cl/portal/1255/articles6228_pdf_ aserraderos.pdf. 2000.

(3) M. Gutierrez, J. Becerra, R. Barra, Bol. Soc. Chilena Quim. 47, 485, (2002)

(4) M. Gutierrez, J. Becerra, J. Godoy, R. Barra, Int. J. Environ. Health Res. 15, 171, (2005)

(5) EPA, Organobromine production wastes; Identification and listing of hazardous waste; Land disposal restrictions; Listing of CERCLA hazardous substances, reportable quantities. [online]. USA; Environmental Protection Agency http://www.epa.gov/epaoswer/hazwaste/state/revision/ frs/fr165.rtf. 1998.

(6) L. Wollenberger, L. Dinan, M. Breitholtz, Environ. Toxicol. Chem. 24, $400,(2005)$

(7) T. Hamers, J. H. Kamstra, E. Sonneveld, A. J. Murk, M. H. A. Kester, P. L. Andersson, J. Legler, A. Brouwer, Toxicological Sciences. 92, 157, (2006)

(8) H. Suty, C. De Traversay, M. Cost, Water Sci. Technol. 49, 227, (2004)

(9) A. Aguiar, A. Ferraz, D. Contreras J. Rodriguez, , Quim. Nova. 30, 623, (2007)

(10) D. Contreras, J. Rodríguez, J. Freer, B. Schwederski, W. Kaim, J.Biol. Inorg. Chem. 12, 1055, (2007)

(11) G. A. Hamilton, J. W. Hanifin, J. P. Friedman, J. Am. Chem. Soc. 88, $5269,(1966)$

(12) D. Contreras, J. Freer, J. Rodriguez, Int. Biodeterior. Biodegrad. 57, 63, (2006)

(13) F. Chen, W. H. Ma, J. J. He, J. C. Zhao, J. Phys. Chem. A. 106, 9485 , (2002)

(14) K. Nam, W. Rodriguez, J. J. Kukor, Chemosphere. 45, 11, (2001)

(15) J. Rodriguez, D. Contreras, C. Parra, J. Freer, J. Baeza, N. Duran, Water Sci. Technol. 40, 351, (1999)

(16) J. Rodriguez, C. Parra, D. Contreras, J. Freer ,J. Baeza, Water Sci. Technol. 44, 251, (2001)

(17) C. Oviedo, D. Contreras, J. Freer, J. Rodríguez, Fresen. Environ. Bull. 12 $1323,(2003)$

(18) B. Barros, I. S. Scarminio, R. E. Bruns Como fazer experimentos. Pesquisa e desenvolvimento na ciência e na indústria., Editora da UNICAMP, Campinas, 2001.

(19) J. J. Pignatello, D. Liu, P. Huston, Environ. Sci. Technol. 33 , 1832, (1999)

(20) D. Zhu, S. Hyun, J. J. Pignatello, L. S. Lee, Environ. Sci. Technol. 38, 436, (2004)

(21) R. Chen, J. J. Pignatello, J. Adv. Oxid. Technol. 4, 447, (1999)

(22) R. Z. Chen, J. J. Pignatello, Environ. Sci. Technol. 31, 239, (1997)

(23) A. Safarzadeh-Amiri, J. R. Bolton, S. R. Carter, J. Adv. Oxid. Technol. 1, $18,(1996)$

(24) E. Kusvuran, A. Samil, O. M. Atanur, O. Erbatur, Appl. Catal. B-Environ. $\mathbf{5 8}, 211,(2005)$

(25) J. Pracht, J. Boenigk, M. Isenbeck-Schroter, F. Keppler H. F. Scholer, Chemosphere. 44, 613, (2001)

(26) M. Monrroy, J. Freer, J. Baeza, J. Rodriguez, Electron. J. Biotechnol. 9, $253,(2006)$

(27) C. Oviedo, D. Contreras, J. Freer, J. Rodriguez, Environ. Technol. 25, $801,(2004)$ 